\title{
Formoterol treatment downregulates the myostatin system in skeletal muscle of cachectic tumour-bearing rats
}

\author{
SÍLVIA BUSQUETS ${ }^{1,2}$, MÍRIAM TOLEDO ${ }^{1}$, ENRICA MARMONTI ${ }^{1}$, MARCEL ORPÍ $^{1}$, EVA CAPDEVILA ${ }^{1}$, \\ ANGELICA BETANCOURT ${ }^{1}$, FRANCISCO J. LÓPEZ-SORIANO ${ }^{1,2}$ and JOSEP M. ARGILÉS ${ }^{1,2}$ \\ ${ }^{1}$ Cancer Research Group, Departament de Bioquímica i Biologia Molecular; Facultat de Biologia, \\ Universitat de Barcelona; ${ }^{2}$ Institut de Biomedicina de la Universitat de Barcelona (IBUB), Barcelona, Spain
}

Received February 17, 2011; Accepted July 4, 2011

DOI: $10.3892 / \mathrm{ol} .2011 .442$

\begin{abstract}
Cachexia is a common systemic manifestation. Additionally, myostatin is known to be a negative regulator of skeletal muscle development. The present study aimed to investigate whether formoterol down-regulates the myostatin system in skeletal muscle of tumour-bearing rats. Real-time PCR and Western blotting were used for the analysis. Results showed that rats bearing the Yoshida AH-130 ascites hepatoma, a cachexia-inducing tumour, exhibited marked muscle wasting that affected the mass of the muscles studied. The cachectic animals exhibited a significant increase in the mRNA levels of the myostatin receptor (ActIIB) in gastrocnemius muscles. Notably, the expression of the various forms of follistatin, a protein with the opposite effects to those of myostatin, was significantly reduced as a result of the implantation of the tumour. When the animals were treated with formoterol, a $\beta$-agonist with anti-cachectic potential, increases in skeletal muscle weights were observed. The $\beta$-agonist significantly increased levels of various follistatin isoforms and significantly decreased the expression levels of the myostatin receptor. In addition, formoterol treatment resulted in a significant decrease of the myostatin protein content of the gastrocnemius muscle. In conclusion, the results presented indicate that certain anabolic actions of formoterol on the skeletal muscle of cachectic animals may be mediated via the myostatin system.
\end{abstract}

\section{Introduction}

In advanced malignant diseases, cachexia appears to be one of the most common systemic manifestations. The presence of cachexia always indicates a poor prognosis, having a marked impact on the patients' quality of life and survival (1).

Correspondence to: Dr Sílvia Busquets, Cancer Research Group, Departament de Bioquímica i Biologia Molecular, Facultat de Biologia, Universitat de Barcelona, Diagonal 645, 08028 Barcelona, Spain

E-mail: silviabusquets@ub.edu

Key words: cachexia, myostatin, muscle wasting, formoterol
Several important molecular mechanisms have been shown to be involved in the increased muscle catabolism observed in cancer-induced cachexia, such as greater ubiquitinproteasome-dependent proteolysis, apoptosis, and activation of uncoupling proteins (2-5). Interaction of these mechanisms leads to muscle-mass loss by promoting protein and DNA breakdown and energy inefficiency.

Myostatin, also known as growth and differentiation factor-8 (GDF factor-8), which was cloned in 1997, is a member of the transforming growth factor- $\beta$ (TGF- $\beta$ ) superfamily of secreted growth factors. It is a negative regulator of skeletal muscle development (6-8). During the embryogenetic process, myostatin expression is only observed in developing skeletal muscles, but the protein continues to be expressed and secreted by skeletal muscles during adult life $(9,10)$. Mice and cattle with genetic deficiencies in myostatin exhibit marked increases in skeletal muscle mass, thus supporting the role of myostatin in supressing muscle growth (11). Myostatin acts systemically (it is produced in muscle and adipose tissue and released in the circulation) and binds to cell-surface receptors, causing muscle loss. The myostatin protein can be detected in the circulation as a full-length precursor that is cleaved into an amino-terminal pro-peptide and a carboxy-terminal mature region, which is the active form of the peptide. In skeletal muscle and circulation, myostatin is detected in inactive complexes of differing composition with other proteins, including its own pro-peptide, follistatin-like 3 (Fstl3, also known as follistatin-related gene), and latent TGF $\beta$ binding protein (12-15). The mechanism of activation of these inactive complexes (or whether they can be activated at all) is unknown. For complexes containing the pro-peptide, activation likely requires proteolysis of the pro-peptide, possibly by specific target cells $(16,17)$. Once activated, myostatin has a high affinity for the activin IIB receptor (Acvr2b, also known as ActRIIB) and a weak affinity for Acvr2a (also known as ActRII and ActRIIA), both of which, as with other receptors for TGF- $\beta$ family members, bind multiple ligands (18).

Skeletal muscle possesses the ability to respond and adapt to changing environmental stimuli, leading to a set of metabolic and morphological adaptations, which allow it to better meet the energy demands of sustained physical activity. Active myostatin binds to its receptor ActRIIB with high affinity and regulates the expression of target genes through a TGF- $\beta$ 
signaling pathway (10). Myostatin signaling acts through this receptor on skeletal muscle by activating an intracellular cascade of events. First, there is presumed recruitment of a type I co-receptor. Thus, activin receptor-like kinases 4 and/or 5 (ALK-4, ALK-5) are candidate coreceptors that are phosphorylated by ActRIIB. This activates phosphorylation of TGF- $\alpha$-specific Smads 2 and 3, which form a complex with Smad 4. The Smad 2/3/4 complex is translocated to the nucleus to regulate the expression of targeted genes such as MyoD and other myogenic regulatory factors (19). Myostatin also activates the p38 MAPK, Erk1/2 and Wnt pathways (10,19-22). Inhibition of myostatin by injection of neutralizing antibodies or antagonists causes an increase in skeletal muscle mass, thus myostatin inhibitors exhibit great potential as candidates for treatment of muscle-wasting diseases $(15,23)$. Conversely, the ectopic expression of myostatin induces atrophy in adult skeletal muscle by decreasing muscle structural genes such as those of myofibrillar proteins (myosin heavy-chain IIb, troponin I and desmin) and myogenic transcription factors (MyoD and myogenin) (24). Myostatin induces muscle wasting by activating the ubiquitin proteolytic system. The ubiquitin-associated genes atrogin-1, MuRF-1 and E214k are upregulated following myostatin treatment (25). Of note, myostatin signaling is able to inhibit Akt phosphorylation, thus downregulating the IGF-1/PI3K/AKT hypertrophy pathway. In addition, myostatin increases the levels of the active form of the transcription factor FoxO1, allowing for increased expression of atrophy-related genes (atrogenes). Notably, myo-

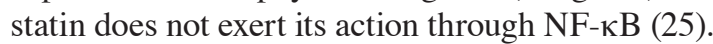

$\beta 2$-adrenergic agonists are potent muscle growth promoters in many animal species $(26,27)$, resulting in skeletal muscle hypertrophy (28-31). Formoterol is one of these compounds with important anti-cachectic effects in animal models. The model of action of this drug is based on its ability to prevent muscle-wasting by inhibiting proteolysis in skeletal muscle. Thus, this $\beta 2$-agonist decreases the activation of the ubiquitin-dependent proteolytic system, the main mechanism activated in muscle-wasting conditions (32). In addition to its anti-proteolytic effects, formoterol decreases muscle apoptosis in muscle-wasting animals (32).

Bearing the above in mind, the aim of the present study was, in addition to observing the myostatin gene expression in a catabolic condition characterised by profound musclewasting implantation of the Yoshida AH-130 ascites hepatoma, to test the hypothesis that certain anabolic actions of formoterol on skeletal muscle (32) involve the myostatin system.

\section{Materials and methods}

Animals. Male Wistar rats (Interfauna, Barcelona, Spain) of 5 weeks of age were used in the experiments. The animals were maintained at $22 \pm 2^{\circ} \mathrm{C}$ with a regular light-dark cycle (light on from 08:00 a.m. to 08:00 p.m.) and had free access to food and water. The food intake was measured daily. All animal manipulations were performed in accordance with the European Community guidelines for the use of laboratory animals.

Tumour inoculation and formoterol treatment. Rats were divided into control and tumour host groups. The latter group received an intraperitoneal inoculum of $10^{8} \mathrm{AH}-130$ Yoshida ascites hepatoma cells obtained from exponential tumours (33). The two groups were further divided into treated and untreated sub-groups, the former being administered a daily subcutaneous dose of formoterol $[0.3 \mathrm{mg} / \mathrm{kg}$ body weight (bw), dissolved in physiological solution], and the latter the corresponding volume of solvent. On day 7 after tumour transplantation, the animals were weighed and anaesthetised with an intra-peritoneal injection of ketamine/ xylazine mixture (3:1) (Imalgene ${ }^{\circledR}$ and Rompun ${ }^{\circledR}$, respectively). The tumour was harvested from the peritoneal cavity and its volume and cellularity were evaluated. Tissues were rapidly excised, weighed, and frozen in liquid nitrogen.

Real-time PCR. Total RNA from the gastrocnemius muscle was extracted by TriPure ${ }^{\mathrm{TM}}$ kit (Roche, Barcelona, Spain), a commercial modification of the acid guanidinium isothiocyanate/phenol/chloroform method (34).

First-strand cDNA was synthesised from total RNA with oligo dT15 primers and random primers pdN6 using a cDNA synthesis kit (Transcriptor Reverse Transcriptase, Roche, Barcelona, Spain). Analysis of mRNA levels for myostatin, ActIIB, FLST288, FLST315, FLST-L3 and Ub was performed with primers designed to detect these products: myostatin (Forward, 5' CTA CCA CGG AAA CAA TCA TTA CCA 3'; Reverse, 5' AGC AAC ATT TGG GCT TTC CAT 3'), ActIIB (Forward, 5' TTG GCT GCG TCT GGA AGG CT 3'; Reverse, 5' TGC CAC GAC TGC TTG TCC TGA 3'), FLST288 (Forward, 5' AGG GAA AGT GTA TCA AAG CAA AGT C 3'; Reverse, 5' AAC CTT GAA ATC CCA TAG GCA TT 3'); FLST315 (Forward, 5' TGC TCC TCC GGC GTA CTG 3'; Reverse, 5' CCG AGA TGG AGT TGC AAG ATC 3'); FLST-L3 (Forward, 5' CCA ACC CTG GCC AAG AAC T 3'; Reverse, 5' AAT GGA ACG GCC CAG AAA G 3'), Ubiquitin (Forward, 5' GAT CCA GGA CAA GGA GGG C 3'; Reverse, 5' CAT CTT CCA GCT GCT TGC CT3') and hydroxymethylbilane synthase (hmbs) (Forward, 5' TGC CAG AGA AAA GTG CCG TGG G 3'; Reverse, 5' TGC AGC TCA TCC AGC TTC CGT 3'), 18S (Forward, 5'-GCG AAT GGC TCA TTA AAT CAG TTA-3'; Reverse, 5'-TGG TTT TGA TCT GAT AAA TGC ACG-3'), p0 (Forward, 5' GAG GTC CTC CTT GGT GAA CA 3'; Reverse, 5' CCT CAT TGT GGG AGC AGA CA 3'). To avoid possible contamination by genomic DNA, primers were designed in different exons. The real-time PCR was performed using a commercial kit (LightCycler ${ }^{\mathrm{TM}} 480$ SYBR-Green I Master, Roche, Barcelona, Spain). The relative amount of all mRNA was calculated using a comparative $\mathrm{Ct}$ method. The average value of $18 \mathrm{~S}, \mathrm{hmbs}$ and acidic ribosomal phosphoprotein p0 mRNA was used as the invariant control for all studies.

Western blotting. Gastrocnemius muscle was homogenised in $10 \mathrm{mmol} / \mathrm{l} \mathrm{HEPES} \mathrm{(pH} \mathrm{7.5),} 10 \mathrm{mmol} / 1 \mathrm{MgCl}_{2}, 5 \mathrm{mmol} / \mathrm{l}$ $\mathrm{KCl}, 0.1 \mathrm{mmol} / \mathrm{l}$ EDTA, $0.1 \%$ Triton $\mathrm{X}-100,1 \mathrm{mmol} / \mathrm{l} \mathrm{DTT}$, and $5 \mu \mathrm{l} / \mathrm{ml}$ of buffer of a protease inhibitor cocktail (Sigma, St. Louis, MO, USA). Tissue homogenates were then centrifuged at 7,000 rpm for $5 \mathrm{~min}$ at $4^{\circ} \mathrm{C}$, and the supernatants were collected. Protein concentrations were determined according to the method of bicinchoninic acid (Pierce Technology, Rockford, IL, USA). Equal amounts of protein 
Table I. Effects of formoterol treatment on gastrocnemius muscle mRNA content of ubiquitin, myostatin, follistatin isoforms and ActIIB receptor and muscle protein content of myostatin in rats bearing the Yoshida AH-130 ascites hepatoma.

\begin{tabular}{|c|c|c|c|c|}
\hline & $\mathrm{C}$ & $\mathrm{C}+\mathrm{F}$ & $\mathrm{T}$ & $T+F$ \\
\hline \multicolumn{5}{|c|}{$\begin{array}{l}\text { Gastrocnemius muscle } \\
\text { mRNA content }\end{array}$} \\
\hline Myostatin & $100 \pm 21$ & $140 \pm 19$ & $102 \pm 23$ & $160 \pm 60$ \\
\hline ActIIB & $100 \pm 12$ & $133 \pm 13$ & $213 \pm 31^{\mathrm{b}}$ & $106 \pm 27^{\mathrm{d}}$ \\
\hline FLSTL3 & $100 \pm 12$ & $94 \pm 16$ & $172 \pm 38$ & $291 \pm 48^{b}$ \\
\hline FLST315 & $100 \pm 21$ & $108 \pm 28$ & $42 \pm 14^{\mathrm{a}}$ & $129 \pm 29^{d}$ \\
\hline FLST288 & $100 \pm 13$ & $55 \pm 10^{\mathrm{d}}$ & $54 \pm 13^{\mathrm{a}}$ & $105 \pm 10^{\mathrm{b}, \mathrm{d}}$ \\
\hline Ubiquitin & $100 \pm 36$ & $90 \pm 16$ & $439 \pm 83^{b}$ & $103 \pm 25^{\mathrm{e}}$ \\
\hline \multicolumn{5}{|l|}{ Protein content } \\
\hline Myostatin $40 \mathrm{kDa}$ & $100 \pm 19$ & $115 \pm 14$ & $98 \pm 14$ & $53 \pm 12^{\mathrm{b}, \mathrm{d}}$ \\
\hline Myostatin $26 \mathrm{kDa}$ & $100 \pm 16$ & $108 \pm 13$ & $106 \pm 10$ & $72 \pm 7^{\mathrm{a}, \mathrm{d}}$ \\
\hline \multicolumn{5}{|l|}{ Heart } \\
\hline \multicolumn{5}{|l|}{ mRNA content } \\
\hline Myostatin & $100 \pm 24$ & $85 \pm 10$ & $67 \pm 7$ & $87 \pm 11$ \\
\hline ActIIB & $100 \pm 15$ & $125 \pm 13$ & $126 \pm 17$ & $140 \pm 23$ \\
\hline FLSTL3 & $100 \pm 12$ & $83 \pm 13$ & $82 \pm 8$ & $94 \pm 13$ \\
\hline FLST315 & $100 \pm 7$ & $118 \pm 21$ & $98 \pm 15$ & $116 \pm 31$ \\
\hline FLST288 & $100 \pm 33$ & $111 \pm 21$ & $74 \pm 13$ & $94 \pm 15$ \\
\hline Ubiquitin & $100 \pm 5$ & $93 \pm 9$ & $143 \pm 4^{c}$ & $119 \pm 9^{\mathrm{d}}$ \\
\hline
\end{tabular}

For more details see the Materials and methods section. Results are the mean \pm SEM for 6 animals in each group. The results of gene and protein expression are expressed as a percentage of controls. C, control animals, T, tumour-bearing rats, F, formoterol-treated rats. Values that were found to be significantly different by the Student's t-test from the non-tumour-bearing animal groups are indicated by ${ }^{\mathrm{a}} \mathrm{p}<0.05,{ }^{\mathrm{b}} \mathrm{p}<0.01$ and ${ }^{\mathrm{c}} \mathrm{p}<0.001$. Values that were found to be significantly different by the Student's t-test from the non-treated animal groups are indicated by ${ }^{\mathrm{d}} \mathrm{p}<0.05$ and ${ }^{\mathrm{e}} \mathrm{p}<0.01$.

(50 or $100 \mu \mathrm{g}$ ) were heat-denatured in sample loading buffer [50 mmol/1 Tris-HCl (pH 6.8), $100 \mathrm{mmol} / \mathrm{l}$ DTT, 2\% SDS, $0.1 \%$ bromophenol blue, $10 \%$ glycerol], resolved by SDS-PAGE (10\% polyacrylamide, $0.1 \%$ SDS), and transferred to Immobilon membranes (Immobilon polyvinylidene difluoride, Millipore, Billerica, MA, USA). The filters were blocked with 5\% PBS non-fat dry milk and then incubated with polyclonal antibody anti-myostatin (Millipore). Mouse antibody anti- $\mathrm{Na}^{+}, \mathrm{K}^{+}$-ATPase $\alpha$ subunit (John Hopkins University, Baltimore, MD, USA) was used as the invariant control. Goat anti-rabbit horseradish peroxidase conjugate (BioRad, Hercules, CA, USA) and HRP-conjugated donkey anti-mouse immunoglobulin-specific monoclonal antibody (Jackson Immuno Research, West Grove, PA, USA) were used as secondary antibodies. The membrane-bound immune complexes were detected by an enhanced chemiluminescence system (EZ-ECL, Amersham Biosciences, Piscataway, NJ, USA).

Statistical analysis. Statistical analysis of the data was performed by means of the Student's t-test.

\section{Results and Discussion}

Fig. 1 shows the implantation of the Yoshida AH-130 ascites hepatoma caused significant decreases in the weight of the gastrocnemius (13\%), EDL (18\%) and tibialis (12\%) muscles. Formoterol treatment significantly increased the weight of the above-mentioned muscles (Fig. 1). These data are in agreement with previous results from our own laboratory (32).

Myostatin has been described as a negative regulator of muscle growth and its development, and is involved in several forms of muscle wasting, including the severe cachexia observed as a result of diseases such as AIDS and cancer $(35,36)$.

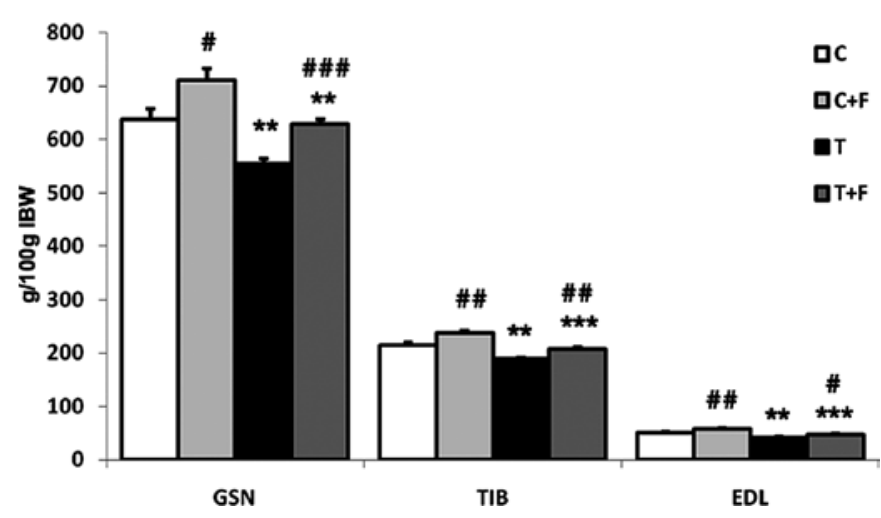

Figure 1. Muscle weights in rats bearing the Yoshida AH-130 ascites hepatoma treated with formoterol. Results are the mean \pm SEM for 7 animals. Muscle weights are expressed as $\mathrm{mg} / 100 \mathrm{~g}$ of initial body weight. GSN, gastrocnemius; TIB, tibialis; EDL, extensor digitorum longus. C, control animals; T, tumour-bearing rats; $\mathrm{F}$, formoterol-treated animals. Values that were found to be significantly different by the Student's t-test from the non-tumour-bearing animal groups are indicated by ${ }^{*} \mathrm{p}<0.05,{ }^{* * *} \mathrm{p}<0.01$ and ${ }^{* * *} \mathrm{p}<0.001$. Values that were found to be significantly different by the Student's t-test from the nontreated animal groups are indicated by ${ }^{\#} \mathrm{p}<0.05,{ }^{\# \#} \mathrm{p}<0.01$ and ${ }^{\# \# \#} \mathrm{p}<0.001$. 
McFarlane et al have demonstrated that myostatin induces cachexia through a NF- $\mathrm{KB}$-independent mechanism by antagonizing hypertrophy signaling through the regulation of the AKT-FOXO1 pathway (25). As with other TGF- $\beta$ superfamily members, myostatin interacts with a serine/threonine transmembrane receptor known as activin IIB (ActIIB) $(22,37,38)$. Binding of the ligand to ActRII leads to phosphorylation and activation of the activin type I receptor, which in turn initiates intracellular signaling mediated by SMAD proteins $(22,37,38)$. Although the levels of gene expression for myostatin were not affected by tumour burden (Table I), the cachectic animals presented a significant increase $(113 \%)$ in the gastrocnemius muscle mRNA levels of the myostatin receptor (ActIIB). This increase indicates that muscle wasting in this experimental tumour model involved the myostatin system. Notably, the expression of the different isoforms of follistatin [FLST288 and FLST315 $(39,40)]$, a protein with the opposite effects to those of myostatin, were significantly reduced as a result of the implantation of the tumour (46 and 58\% for FLST288 and FLST315, respectively, Table I). This observation further supports a role for the myostatin system in muscle wasting in the Yoshida AH-130 ascites hepatoma model.

Follistatin is a secreted protein capable of binding and neutralising the actions of any member of the TGF- $\beta$ family of proteins such as myostatin. In addition to our finding that follistatin is decreased in tumour-bearing animals, two independent approaches provide clear evidence that downregulation of this gene contributes to the atrophic phenotype in cachectic muscles. One approach is based on the observation that follistatin is required to increase the muscle capillary density and improve endothelial cell function in ischemic mice and that its expression is associated with AKT1 signaling (41). This result indicates that follistatin downregulation in cachectic muscles leads to a decrease in AKT1 expression resulting in a decreased protein synthesis (41). The other approach, using transgenic mice and $\mathrm{C} 2 \mathrm{C} 12$ cells overexpressing follistatin, demonstrated that follistatin over-expression in mouse skeletal muscle promotes hypertrophy and an oxidative fibre-type switch, leading to increased whole-body strength and fatigue resistance; follistatin overexpression enhances myoblast fusion, resulting in hypertrophic myotubes in $\mathrm{C} 2 \mathrm{C} 12$ cells, acting via regulation of the CnA-NFAT pathway (42). Our results are in agreement with those of Costelli et al who observed similar changes in both myostatin and follistatin mRNA levels in gastrocnemius muscles of tumour-bearing rats at day 4 of tumour growth (36). However, at later stages of tumour growth (day 7, as used in the present study) the same authors observed increased myostatin and follistatin mRNA levels. The reasons for this discrepancy are not known.

No changes in myostatin, myostatin receptor or follistatin mRNA were observed in the heart of the tumour-bearing animals (Table I). This indicates that the myostatin system does not appear to be responsible for cardiac muscle wasting. Similar observations have been made in patients with chronic heart failure (43).

When the animals were treated with formoterol, a $\beta$-agonist with anti-cachectic potential (32), in addition to an anabolic action of skeletal muscle that was clearly reflected on increases in muscle weights [gastrocnemius (13\%), tibialis (10\%) and
EDL (12\%) (Fig. 1)], the $\beta$-agonist significantly decreased ubiquitin gene expression (Table I). This is a clear marker of protein degradation, a process that has extensively been described during muscle wasting (44-49). Formoterol treatment significantly increased the two follistatin isoforms (94\% for FLST288 and $201 \%$ for FLST315) as well as the FLSTL3 $(69 \%)$, termed FLST-like 3. FLSTL3 is a protein that has recently been discovered to share significant structural and functional homology with follistatin (50). Moreover, treatment significantly decreased the levels of expression of the myostatin receptor $(50 \%)$ (Table I). In addition, formoterol treatment resulted in a significant decrease in the myostatin protein content [both active $(32 \%)$ and inactive myostatin (46\%)] of gastrocnemius muscle (Table I). It is clear that the antiwasting effects of formoterol involve the myostatin system.

In conclusion, the results presented indicate that certain anabolic actions of formoterol on the skeletal muscle of cachectic animals may be mediated via the myostatin system. This treatment modality should therefore be regarded as a potential therapeutic target in cancer cachexia.

\section{Acknowledgements}

This study was supported by a grant from the Ministerio de Ciencia y Tecnología (SAF-02284-2008). The authors would like to thank Industriale Chimica s.r.l. (Saronno, Italy), who kindly provided micronised formoterol fumarate.

\section{References}

1. Harvey KB, Bothe A Jr and Blackburn GL: Nutritional assessment and patient outcome during oncological therapy. Cancer 43: 2065-2069, 1979.

2. Argiles JM, Alvarez B and Lopez-Soriano FJ: The metabolic basis of cancer cachexia. Med Res Rev 17: 477-498, 1997.

3. Argiles JM and Lopez-Soriano FJ: The ubiquitin-dependent proteolytic pathway in skeletal muscle: its role in pathological states. Trends Pharmacol Sci 17: 223-226, 1996.

4. Sanchis D, Busquets S, Alvarez B, Ricquier D, Lopez-Soriano FJ and Argiles JM: Skeletal muscle UCP2 and UCP3 gene expression in a rat cancer cachexia model. FEBS Lett 436: 415-418, 1998.

5. Van Royen M, Carbo N, Busquets S, et al: DNA fragmentation occurs in skeletal muscle during tumor growth: A link with cancer cachexia? Biochem Biophys Res Commun 270: 533-537, 2000.

6. Lee SJ and McPherron AC: Myostatin and the control of skeletal muscle mass. Curr Opin Genet Dev 9: 604-607, 1999.

7. Sharma M, Langley B, Bass J and Kambadur R: Myostatin in muscle growth and repair. Exerc Sport Sci Rev 29: 155-158, 2001.

8. Tsuchida K: Targeting myostatin for therapies against musclewasting disorders. Curr Opin Drug Discov Devel 11: 487-494, 2008.

9. McPherron AC, Lawler AM and Lee SJ: Regulation of skeletal muscle mass in mice by a new TGF-beta superfamily member. Nature 387: 83-90, 1997.

10. Elkasrawy MN and Hamrick MW: Myostatin (GDF-8) as a key factor linking muscle mass and bone structure. J Musculoskelet Neuronal Interact 10: 56-63, 2010.

11. Lee SJ: Sprinting without myostatin: a genetic determinant of athletic prowess. Trends Genet 23: 475-477, 2007.

12. Lee SJ: Regulation of muscle mass by myostatin. Annu Rev Cell Dev Biol 20: 61-86, 2004.

13. Anderson SB, Goldberg AL and Whitman M: Identification of a novel pool of extracellular pro-myostatin in skeletal muscle. J Biol Chem 283: 7027-7035, 2008.

14. Hill JJ, Davies MV, Pearson AA, et al: The myostatin propeptide and the follistatin-related gene are inhibitory binding proteins of myostatin in normal serum. J Biol Chem 277: 40735-40741, 2002 . 
15. Guo T, Jou W, Chanturiya T, Portas J, Gavrilova $O$ and McPherron AC: Myostatin inhibition in muscle, but not adipose tissue, decreases fat mass and improves insulin sensitivity. PLoS One 4: e4937, 2009

16. Wolfman NM, McPherron AC, Pappano WN, et al: Activation of latent myostatin by the BMP-1/tolloid family of metalloproteinases. Proc Natl Acad Sci USA 100: 15842-15846, 2003.

17. Lee SJ: Genetic analysis of the role of proteolysis in the activation of latent myostatin. PLoS One 3: e1628, 2008.

18. De Caestecker M: The transforming growth factor-beta superfamily of receptors. Cytokine Growth Factor Rev 15: 1-11, 2004

19. Rodino-Klapac LR, Haidet AM, Kota J, Handy C, Kaspar BK and Mendell JR: Inhibition of myostatin with emphasis on follistatin as a therapy for muscle disease. Muscle Nerve 39: 283-296, 2009

20. Allendorph GP, Vale WW and Choe S: Structure of the ternary signaling complex of a TGF-beta superfamily member. Proc Natl Acad Sci USA 103: 7643-7648, 2006.

21. Steelman CA, Recknor JC, Nettleton D and Reecy JM: Transcriptional profiling of myostatin-knockout mice implicates Wnt signaling in postnatal skeletal muscle growth and hypertrophy. FASEB J 20: 580-582, 2006.

22. Joulia-Ekaza D and Cabello G: The myostatin gene: physiology and pharmacological relevance. Curr Opin Pharmacol 7: 310-315, 2007

23. Whittemore LA, Song K, Li X, et al: Inhibition of myostatin in adult mice increases skeletal muscle mass and strength. Biochem Biophys Res Commun 300: 965-971, 2003.

24. Durieux AC, Amirouche A, Banzet S, et al: Ectopic expression of myostatin induces atrophy of adult skeletal muscle by decreasing muscle gene expression. Endocrinology 148: 3140-3147, 2007.

25. McFarlane C, Plummer E, Thomas M, et al: Myostatin induces cachexia by activating the ubiquitin proteolytic system through an NF- $\mathrm{KB}$-independent, FoxO1-dependent mechanism. J Cell Physiol 209: 501-514, 2006.

26. Stock MJ and Rothwell NJ: Effects of $\beta$-adrenergic agonists on metabolism and body composition. In: Control and manipulation of Animal Growth. Buttery PJ, Hayes NB and Lindsay DB (eds.) Butterworths, London, pp249-257, 1985.

27. Kim YS and Sainz RD: Beta-adrenergic agonists and hypertrophy of skeletal muscles. Life Sci 50: 397-407, 1992

28. Agbenyega ET and Wareham AC: Effect of clenbuterol on skeletal muscle atrophy in mice induced by the glucocorticoid dexamethasone. Comp Biochem Physiol Comp Physiol 102: 141-145, 1992.

29. Rajab P, Fox J, Riaz S, Tomlinson D, Ball D and Greenhaff PL: Skeletal muscle myosin heavy chain isoforms and energy metabolism after clenbuterol treatment in the rat. Am J Physiol Regul Integr Comp Physiol 279: R1076-R1081, 2000.

30. Hinkle RT, Hodge KM, Cody DB, Sheldon RJ, Kobilka BK and Isfort RJ: Skeletal muscle hypertrophy and anti-atrophy effects of clenbuterol are mediated by the beta2-adrenergic receptor. Muscle Nerve 25: 729-734, 2002.

31. Wineski LE, von Deutsch DA, Abukhalaf IK, Pitts SA, Potter DE and Paulsen DF: Muscle-specific effects of hindlimb suspension and clenbuterol in mature male rats. Cells Tissues Organs 171: 188-198, 2002

32. Busquets S, Figueras MT, Fuster G, et al: Anticachectic effects of formoterol: a drug for potential treatment of muscle wasting. Cancer Res 64: 6725-6731, 2004.

33. Tessitore L, Costelli P, Bonetti G and Baccino FM: Cancer cachexia, malnutrition, and tissue protein turnover in experimental animals. Arch Biochem Biophys 306: 52-58, 1993.
34. Chomczynski P and Sacchi N: Single-step method of RNA isolation by acid guanidinium thiocyanate-phenol-chloroform extraction. Anal Biochem 162: 156-159, 1987.

35. Gonzalez-Cadavid NF, Taylor WE, Yarasheski K, et al Organization of the human myostatin gene and expression in healthy men and HIV-infected men with muscle wasting. Proc Natl Acad Sci USA 95: 14938-14943, 1998.

36. Costelli P, Muscaritoli M, Bonetto A, et al: Muscle myostatin signalling is enhanced in experimental cancer cachexia. Eur J Clin Invest 38: 531-538, 2008.

37. Joulia-Ekaza D and Cabello G: Myostatin regulation of muscle development: molecular basis, natural mutations, physiopathological aspects. Exp Cell Res 312: 2401-2414, 2006.

38. Kollias HD and McDermott JC: Transforming growth factor-beta and myostatin signaling in skeletal muscle. J Appl Physiol 104: 579-587, 2008

39. Shimasaki S, Koga M, Esch F, et al: Primary structure of the human follistatin precursor and its genomic organization. Proc Natl Acad Sci USA 85: 4218-4222, 1988.

40. Aoki MS, Soares AG, Miyabara EH, Baptista IL and Moriscot AS: Expression of genes related to myostatin signaling during rat skeletal muscle longitudinal growth. Muscle Nerve 40: 992-999, 2009.

41. Ouchi N, Oshima Y, Ohashi K, et al: Follistatin-like 1, a secreted muscle protein, promotes endothelial cell function and revascularization in ischemic tissue through a nitric-oxide synthase-dependent mechanism. J Biol Chem 283: 32802-32811, 2008.

42. Cowling BS, McGrath MJ, Nguyen MA, et al: Identification of FHL1 as a regulator of skeletal muscle mass: implications for human myopathy. J Cell Biol 183: 1033-1048, 2008.

43. Zamora E, Lupon J, Simo R and Galan A: Myostatin serum levels in heart failure. Eur J Heart Fail 12: 1379; author reply 1379-1380, 2010

44. Llovera M, Carbo N, Lopez-Soriano J, et al: Different cytokines modulate ubiquitin gene expression in rat skeletal muscle. Cancer Lett 133: 83-87, 1998.

45. Llovera M, Garcia-Martinez C, Agell N, et al: Ubiquitin and proteasome gene expression is increased in skeletal muscle of slim AIDS patients. Int J Mol Med 2: 69-73, 1998.

46. Llovera M, Garcia-Martinez C, Lopez-Soriano J, et al: Role of TNF receptor 1 in protein turnover during cancer cachexia using gene knockout mice. Mol Cell Endocrinol 142: 183-189, 1998.

47. Llovera M, Garcia-Martinez C, Agell N, Lopez-Soriano FJ and Argiles JM: Muscle wasting associated with cancer cachexia is linked to an important activation of the ATP-dependent ubiquitin-mediated proteolysis. Int J Cancer 61: 138-141, 1995.

48. Garcia-Martinez C, Llovera M, Agell N, Lopez-Soriano FJ and Argiles JM: Ubiquitin gene expression in skeletal muscle is increased by tumour necrosis factor-alpha. Biochem Biophys Res Commun 201: 682-686, 1994.

49. Llovera M, Garcia-Martinez C, Agell N, Marzabal M, LopezSoriano FJ and Argiles JM: Ubiquitin gene expression is increased in skeletal muscle of tumour-bearing rats. FEBS Lett 338 311-318, 1994

50. Schneyer A, Tortoriello D, Sidis Y, Keutmann H, Matsuzaki T and Holmes W: Follistatin-related protein (FSRP): a new member of the follistatin gene family. Mol Cell Endocrinol 180: 33-38, 2001. 